the patient had experienced a strange and disagreeable sensation in the lower part of the left thigh and upper two-thirds of the leg, coming on from five to fifteen minutes after he had sat down. This feeling would increase more and more, forcing him finally to stretch the leg, after which he experienced a tendency to stand up. Yielding to this would cause the paræsthesia to disappear. So pronounced was the symptom that he had obtained permission at school to stand up every fifteen minutes during his lessons.

Examination of the nervous system revealed exaggerated knee-jerks and a tendency to ankle clonus. The plantar reflex was variable, sometimes a true extensor response being provoked, and at others extension of all the toes and foot. A vibratory hyperæsthesia of the left leg was demonstrable with the tuning-fork.

Subsequent to the objective examination, which strongly impressed the patient, his symptoms disappeared, and he was able to remain seated for prolonged periods without difficulty. His cure the author attributes to auto-suggestion, the result of this examination.

The association of Babinski's sign with a functional disorder is noteworthy. This, and the other signs usually indicative of organic disease, disappeared after a short time.

H. Devine.

\title{
The Loss of "Sentiments of Worth" in Mental Depression [La Perte des Sentiments de Valeur dans la Depression Mentale]. (Journ. de Psychol., vi, r908.) Janet, Pierre.
}

The case described by the author in this paper is that of a girl, æt. 23, who, before her present illness, had been intelligent and had occupied a responsible position in a business house. Following a brief period of confusion and excitement a state of inertia and perplexity developed, the most noticeable feature of which was a tendency to touch and examine every object she came across in aimlessly wandering about the house. She displayed various strange alterations of feelings, viz. :

(I) A sentiment of not existing, and a feeling that events did not occupy time. There was no actual amnesia, only a feeling that the events occurring since her illness lacked any temporal relations.

(2) A feeling of fear together with a curious attitude of defiance. Explaining that she is afraid of making a stupid mistake she refuses to do anything unless someone else does the same thing first. Thus, she will not eat unless the nurse eats with her, and eats exactly the same things.

(3) A feeling of doubt in regard to herself and everything about her, leading her to examine minutely everything she sees to try and convince herself of its reality. This attitude of doubt only exists for objects or persons known before her illness. New objects she recognises perfectly and does not need to verify their reality; they have for her, however, one common characteristic - that of baseness. They are all deprived of everything that can please or interest in any way whatever. Any article which is purchased is cheap, common, an imitation, inartistic, disgusting. She applies similar criticisms to her food, water, medicine-everything is bad. This peculiar variety of "incompleteness" the writer summarises under a loss of sentiments of worth. He briefly discusses the case, showing that these alterations of feeling 
depend on a defect of attention and a change in the psychological "tension" rather than any cœnæsthetic disorder. The diagnosis lies between an early phase of dementia præcox and manic-depressive insanity.

H. Devine.
On Great Mental Depression arising from Political Events [Über psychische Störung depressiver Natur. entstand en auf dem Boden der gegenwartigen politischen Erieignisse]. (Allg. Zeits., Bd. 64, H. i.) Hermann, $N$.

Dr. Hermann observes that while passions, such as anguish, distress and terror in some cases prepare the way for mental derangement by weakening the nervous system, in others these emotions become the immediate causes of insanity, especially with individuals predisposed by hereditary degeneration. The unhappy condition of Russia, owing to the Japanese war, famine, and the political disorders and massacres, has thrown the whole population into a state of uncertainty and fear. Amongst the soldiers who took part in the war a peculiar form of insanity has been described, in which depression, stupor, and mental confusion were prominent symptoms. These were occasionally attended by incoherent delusions, ideas of persecution, and self-accusations. In addition to these affections amongst the soldiers, Rybakow has described twelve cases of insanity in the civil population which seemed to be caused by painful political events. Almost all of these exhibited the same form-great distress, restlessness, delusions of persecution, and, in most cases, illusions of the senses of a distressing character. Dr. Hermann, Superintendent of the Government Asylum at Orel, now contributes seven cases, occurring in the civil population, with similar symptoms. He has especially excluded patients in which there was an abuse of alcohol. In the cases described by him, the period of incubation was not marked, and only lasted one or two days. In some, the mental derangement followed immediately after the shock. Besides the extreme mental depression, most of the patients had hallucinations of sight and hearing, often of a distressing nature. They heard threats that someone would kill them; they heard the sobbing of people who had been thrown into the fire; loud noises, and voices of enchanters. They saw people thrown into a fiery furnace; they saw witches, and one saw Satan floating in the air above him. They saw mobs of people coming out of the earth. One patient had an hallucination of smell, which gave him much annoyance. While the mental condition in all these patients was one of overpowering distress, there was no selfaccusation. The delusions were not of a systematised character, nor directed against special persons, but indicated a condition of general alarm and misery. The prognosis in this form of insanity was found to be good, and the duration of the attack was short. Out of Hermann's patients, four recovered soon, two were in the way of recovery, and the seventh was uncertain.

William W. IREland.

The Mental State in Chorea and Choreiform Affections. (Journ. Nerv. and Ment. Dis., June, 1908.) Burr, C.W.

Professor Burr, in his Presidential Address to the American Neurological Association on this subject, regrets that the word "chorea" cannot 